\title{
Traumatic Angle Recession with Secondary Glaucoma- A Case Series Study
}

\author{
Dr. Shams Mohammed Noman ${ }^{1 *}$, Dr Shailendra Sugrim², Dr Ishtiaque Anwar ${ }^{3}$, Dr Indira Paudyal ${ }^{4}$ and Dr \\ Umme Salma Akbar ${ }^{5}$ \\ ${ }^{1}$ Department of Ophthalmology, Bangabandhu shekh mujib medical university, Bangladesh
}

${ }^{2}$ Glaucoma consultant, Georgetwon public hospital corporation, Guyana

${ }^{3}$ Asst Prof, Bangladesh eye hospital and institute, Bangladesh

${ }^{4}$ Glaucoma Consultant, Tilganga Institute of Ophthalmology, Nepal

${ }^{5}$ Senior Assistant Surgeon,Chittagong Eye Infirmary and training complex,Bangladesh

*Corresponding author: Dr Shams Mohammed Noman Associate Prof of Ophthal-

Received Date: April 21, 2021

mology, Bangabondhu Shekh Mujib Medical University, Bangladesh.

\begin{abstract}
Purpose: To describe the patterns of outcomes and management approaches to patients diagnosed with angle recession glaucoma presenting at the Glaucoma Department, Chittagong Eye Infirmary \& Training Complex, Bangladesh.

Design: A hospital-based prospective observational case series review.

Participants: 25 patients who were diagnosed with angle recession glaucoma over a 1-year period from November 1st 2009 to October 31st 2011.

Method: Patient particulars, history and mechanism of trauma were recorded. Ophthalmic examination details (including gonioscopy, intraocular pressure and fundoscopy) and management given were documented. Similar relevant details were recorded for three follow-up periods, on all patients, extending over a total period of 9 months.

Results: 25 patients with angle recession glaucoma were included in the study. Twenty-two of the patients were male. The mean age of patients was $34.9 \pm 20.84$ years (Range: $9-72 \mathrm{yrs}$ ). All patients had an angle cleavage of more than 180 degrees, with $68 \%$ having a recession of 360 degrees. $56 \%$ had a history of hyphaema. In $88 \%$ of patients, the intra-ocular pressure (IOP) was controlled and kept at a stable level $(<21 \mathrm{mmHg})$ over follow-up. Of these, $91 \%$ were controlled by conservative treatment (topical anti-glaucoma drugs or observation) and $9 \%$ was controlled after cataract surgery. Patients with uncontrolled IOP (12\%) were advised for filtration surgery. The mean IOP at time of diagnosis was $29.8 \pm 9.7 \mathrm{mmHg}$ (Range: $14-50 \mathrm{mmHg}$ ). The mean IOP at last follow-up was $18.4 \pm 8.4 \mathrm{mmHg}$ (Range: $10-50 \mathrm{mmHg}$ ). Visual Acuity (VA) for 23 patients ( $92 \%$ ) either remained stable or improved.

Conclusion: Angle recession glaucoma can cause further loss of vision in ocular trauma patients who may already have compromised vision due to injury. Control of IOP and preservation of presenting VA was seen in most cases with conservative management with topical medications and sustained follow-up. Patients sustaining blunt ocular trauma, especially those associated with hyphaema, should be advised for future follow up and have gonioscopic evaluation of the angle.
\end{abstract}

\section{Introduction}

One of the long-term effects of eye injuries is the development of angle recession and subsequently Angle Recession Glaucoma (ARG). $60-94 \%$ of patients who have suffered blunt ocular injury

have some degree of either angle recession or trabecular membrane damage [1-3]. The prevalence of people with angle recession was shown to be $5.5 \%$ from a study done in South Africa.4 Another study 
in the Cameroon5 showed a prevalence of post-traumatic glaucoma, related to irido-corneal angle injuries, to be $2.1 \%$. In a study done in India [4] at an urban referral centre, shows a prevalence of 34 per 1000 glaucoma cases. 4 - 9\% of patients with angle recession greater than 180 degrees eventually develop glaucoma [1,2,5-7]. Even though the condition is referred to as "angle recession" (i.e the splitting of the circular and longitudinal muscles of the ciliary body), the real pathology behind the development of raised IOP is not the cleavage in itself. Wolf and Zimmerman [8] suggested that the recession is only evidence of past trauma and not the cause of the glaucoma in itself. It was suggested that initial trauma to the trabecular meshwork stimulated proliferative or degenerative changes in the trabecular tissue, which led to the obstruction of aqueous flow. Herschler11 supported this concept. Other mechanisms for delayed IOP elevation, in addition to alterations within the trabecular meshwork, include the extension of an endothelial layer with a descemet-like membrane from the corner over the angle [8]. So despite some injury patients being able to salvage some amount of functionable vision after injury repair and rehabilitation, they are still susceptible to further visual loss due to ARG (secondary damage). Thus, treatment of a patient with a history of ocular trauma does not end with the initial management of acute complications due to the injury itself. As seen, various mechanisms can lead to ocular hypertension and eventually optic nerve damage leading to glaucoma and, in severe cases, blindness. ARG is usually managed in a step-wise manner. First medically and then via laser therapy [9]. Patients may not initially respond well to standard medical therapy and management options may usually lead to surgical procedures [10]. When medical and laser therapies have failed, an incisional outflow operation is usually indicated, such as trabeculectomy with mitomycin C [11-13] or valve implantation. This study was done at the Chittagong Eye Infirmary and Training Complex (CEITC), one of the largest tertiary level ophthalmic centre in Bangladesh. It is the purpose of this study is to document and analyse the various patterns of outcomes and management approaches to patients diagnosed with ARG.

\section{Method}

This was a hospital-based combined non-concurrent and concurrent prospective cohort study of all cases presenting to the Glaucoma Department with a diagnosis of ARG. Cases were identified throughout a one-year period from November 1st 2009 to October 31st 2011. All patients were reviewed by a single consultant who took the history and necessary ophthalmic examination. Details of history included the biographical details of patients (age, gender, address etc), history and mechanism of trauma. Ophthalmic examination was done on patients and examination details included visual acuity (VA); intra-ocular pressure (IOP) measurement by Goldmann Applanation Tonometer; gonioscopic findings by Goldmann 2-mirror contact goniolens; fundoscopic findings and any other notable ocular findings. The method of management was recorded. Diagnosis of ARG was done based on a combination of history, gonioscopic findings, fundoscopic findings and IOP readings. For previously diagnosed patients, their medical records were retrieved, and relevant data were extracted and asked to come for follow-up as necessary. Newly diagnosed patients were duly processed and asked to return for future follow-up visits. At least three follow-up data were recorded, 1 month after diagnosis of ARG, then 3 months and 6 months. On all visits ophthalmic examination was done by the same consultant. After collection of data, they were then tabulated and analyzed. Outcomes of management was assessed mainly with regards to IOP control. Statistical analysis was done using SPSS v.13.

\section{Results}

A total number of 25 patients with ARG were encountered during the study period. The total number of eyes affected was 25 . Of these, 14 (56\%) were newly diagnosed cases and 11 (44\%) were previously diagnosed patients (Figure $1 \&$ Table 1 ).

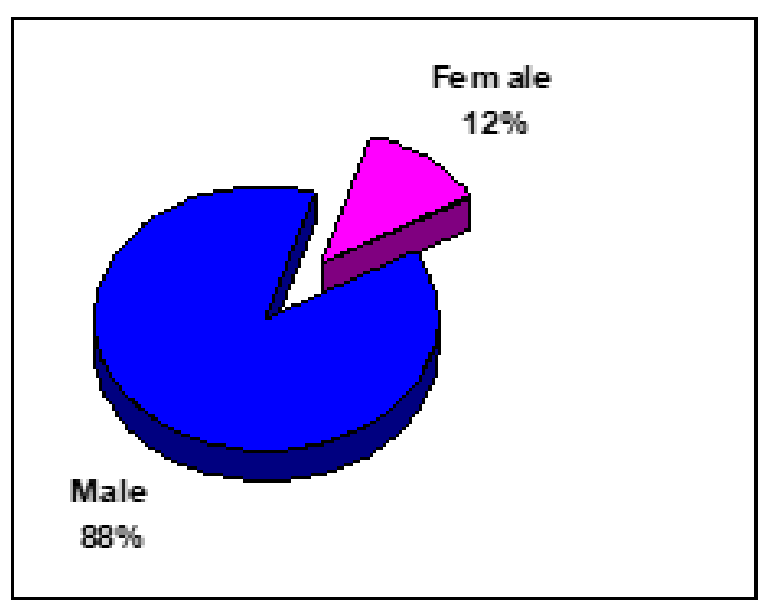

Figure 1: Gender Distribution of patients. 
Table 1: Gender Distribution of patients in the defined Age Categories $(p<0.4)$.

\begin{tabular}{|c|c|c|c|c|}
\hline \multicolumn{2}{|c|}{ Male } & \multicolumn{2}{c|}{ Gender } & \multicolumn{2}{c|}{ Total } \\
\cline { 2 - 4 } & $0-19$ years & Female & 2 & $8(32 \%)$ \\
\hline \multirow{3}{*}{ Age Groups } & $20-39$ years & 6 & 1 & $6(24 \%)$ \\
\cline { 2 - 5 } & $40-59$ years & 6 & 0 & $6(24 \%)$ \\
\cline { 2 - 5 } & $60-79$ years & 5 & 0 & $5(20 \%)$ \\
\hline \multicolumn{2}{|c|}{ Total } & 22 & 3 & $25(100 \%)$ \\
\hline
\end{tabular}

$22(88 \%)$ of the patients were male and $3(12 \%)$ were female Figure 1 . The mean age of patients was $34.9 \pm 20.84$ years, ranging from 9 years to 72 years. With regards to the age group of patients,
8 patients (32\%) were in the $0-19$ years category and 5 patients $(20 \%)$ in the $60-79$ years category. In all age group categories males were more than females Table $1 \mathrm{p}<0.4$ (Table 2).

Table 2: Degree of Angle Cleavage found on Gonioscopic Examination.

\begin{tabular}{|c|c|c|c|}
\hline Degree of Angle Cleavage & Number & Percent & Cumm Percent \\
\hline 360 degrees & 17 & $68 \%$ & $68 \%$ \\
\hline 270 degrees & 4 & $16 \%$ & $84 \%$ \\
\hline 180 degrees & 4 & $16 \%$ & $100 \%$ \\
\hline TOTAL & 25 & $100 \%$ & $100 \%$ \\
\hline
\end{tabular}

All of our patients had an angle cleavage of more than 180 degrees, with $84 \%$ having an angle of recession more than 270 degrees and 17 patients (68\%) having a degree of angle recession of 360 degrees Table 2.14 patients (56\%) had a history of hyphaema at the time of injury, whilst 8 patients $(32 \%)$ had associated traumatic cataract. Other associated clinical findings included lens subluxation, sphincter rupture, macula hole and choroidal rupture. $56 \%$ had a history of trauma 1 year to 5 years prior. $28 \%$ had history of trauma occurring less than 1 year ago. In 22 patients (88\%), the IOP was controlled and kept at a stable level $(<21 \mathrm{mmHg})$ over the follow-up periods and in 3 patients $(12 \%)$ the IOP was not controlled (even after the use of three-drug anti-glaucoma topical therapy). The mean IOP at time of diagnosis of Angle Recession Glaucoma was $29.8 \pm 9.7 \mathrm{mmHg}$ (Range: $14-50 \mathrm{mmHg}$ ). The mean IOP at last follow-up was $18.4 \pm 8.4 \mathrm{mmHg}$ (Range: $10-50 \mathrm{mmHg}$ ). Of the 22 patients whose IOP were controlled, 20 (91\%) were controlled by conservative treatment (use of single or dual topical anti-glaucoma drugs or by observation). The remaining 2 patients (9\%) had surgical intervention (Small Incision Cataract Surgery in both cases). Patients with uncontrolled IOP (12\%) were advised for filtration surgery (Figure 2).

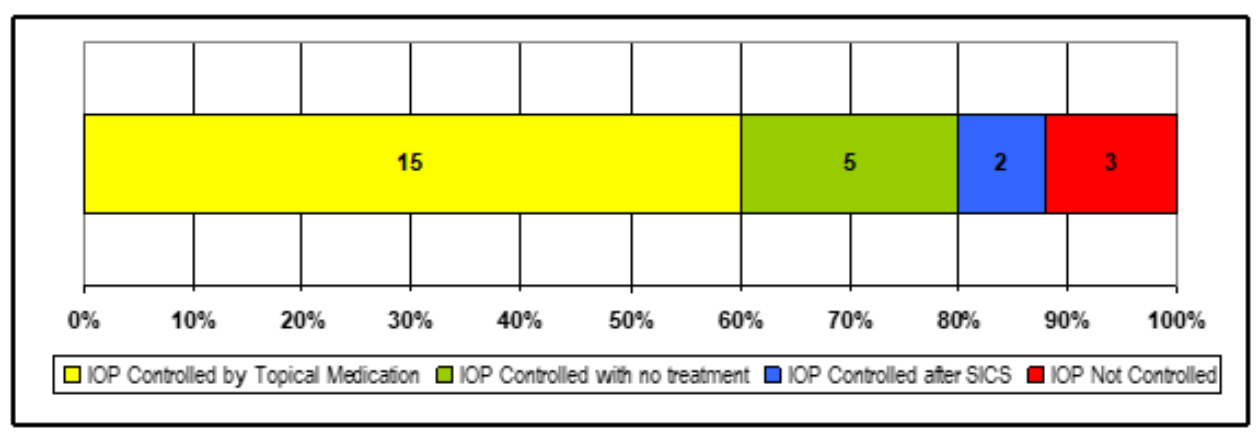

Figure 2: Management approach for the control of IOP.

The VA for 23 patients (92\%) either remained stable or improved, in 2 (8\%) patients the VA worsened. The last recorded VA of patients in the follow-up showed 7 patients (28\%) having a VA of $6 / 18$ and better, whilst 13 patients (52\%) had a VA ranging from $6 / 24$ to $3 / 60.5$ patients (20\%) had a VA of CF at $1 / 2 \mathrm{~m}$ and worse.

\section{Discussion}

The effects of the injury itself on the eye can be very devastating (i.e primary damage due to the injury). It is estimated globally that 1.6 million cases of blindness are caused by eye injuries and a further 2.3 million cases with low vision are caused by eye injuries [14]. Approximately 19 million cases of monocular 
blindness are estimated to be due to eye injuries [14]. According to a report by Therefore [15] particularly in developing countries (like Bangladesh), trauma is often the most important cause of unilateral loss of vision (as much as $5 \%$ of all blindness). It further states that males tend to have more eye trauma than females and that lower socioeconomic classes are more associated with ocular trauma. Despite some amount of initial loss of vision sustained by the patient (whether due to traumatic corneal scarring, or choroidal rupture etc), they are susceptible to further loss of vision due to ARG. In literature and studies it has been shown that ARG can develop as soon as within years, or even decades after the trauma. One study showed mean duration of 16 years [16] one done in South Africa showed a latency period of 7.6 \pm 9.5 years [11] whilst a study in Cameroon showed a shorter period of $3.7 \mathrm{yrs}$ [17]. Thus, patients who sustain ocular injuries need to be assessed indefinitely to preserve whatever remaining visual function they have to prevent secondary damage. Our study showed majority of our patients $(56 \%)$ with a latency period within the range of 1 year to 5 years. These findings, along with those of other studies, show that we cannot define a specific time period of the development of ARG, thus reinforcing the need for life-long follow-up of trauma patients. ARG is expected to be more common in males $[18,19]$ due to the fact that males are more predisposed to have ocular injuries in general (an accepted global pattern showed by many international studies in developing and developed countries) [2025]. This trend is in keeping with those found in our study which showed that $88 \%$ of our patients were male Figure 1 and that the male to female ratio in all age groups was consistently higher Table 1 . The mean age of our patients was $34.9 \pm 20.84$ years with a wide range from 9 years to 72 years. A similar wide range was seen in a study in the Cameroon 5 (with a range of 17 to 67; Mean $45.9 \pm 18.3$ years). Though advanced age is associated with ARG, in our study 8 patients (32\%) were in the $0-19$ years category and 5 patients
$(20 \%)$ in the $60-79$ years category Table 1 . Our data shows a fairly even distribution amongst the various age groups with a slight peak in the younger age group ( $0-19$ years). We attribute this to the fact that younger patients are more susceptible to ocular trauma $[21,26]$. There are a few proven identifying risk factors that can assist in predicting if a patient with ocular will develop ARG. Some of these include poor initial visual acuity, advanced age, lens injury, angle recession, hyphaema [6] elevated baseline IOP and angle recession of more than 180 degrees [7,27]. Many studies in developing and developed countries have shown the association between hyphaema and angle recession [4,6,27-29]. Patients who have hyphaema at time of injury are more likely to develop angle recession. In Iran [30] 62\% of patients with hyphaema had angle recession of more than 180 degrees. One study from Portugal31 showed a $55.6 \%$ incidence of AR in patients with hyphaema. 56\% of our patients had a history of hyphaema at the time of injury. Presence of hyphaema signifies compromise to the blood vessels of the anterior uvea (iris and/or ciliary body). Thus, the management of patients presenting with hyphaema needs to include gonioscopic evaluation of the angle at some point. This can at least help us to guide the future management of our trauma patients and to prevent any further loss of vision. Other associated clinical features found in our patients included traumatic cataract (32\%), sphincter rupture, subluxated lens, posterior segment involvement (such as choroidal rupture and macula hole). All of our patients had a degree of angle cleavage of more than 180 degrees with 17 (68\%) of the patients having a degree of angle recession of 360 degrees Table 2 . This correlates with the general fact that patients with an angle recession of more than 180 degrees or more are more susceptible to developing glaucoma [1,3,5-7]. Apart from this, we had a higher number of patients with angle recessions more than 270 degrees Figure 3 when compared to other similar studies [19,30] (Figure 3).

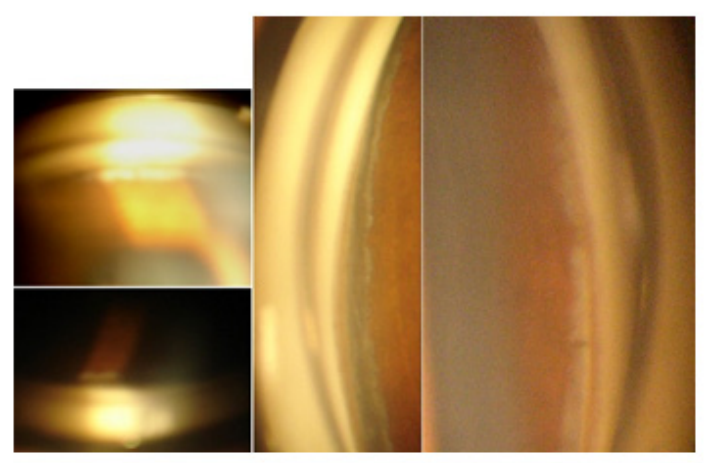

Figure 3: Wide ciliary body band seen on gonioscopy.

The mean IOP at the time of diagnosis of Angle Recession Glaucoma was $29.8 \pm 9.7 \mathrm{mmHg}$ (Range: $14-50 \mathrm{mmHg}$ ). The mean IOP at last follow-up was $18.4 \pm 8.4 \mathrm{mmHg}$ (Range: $10-50 \mathrm{mmHg}$ ) $(p<0.017)$. This is slightly lower than findings of a study done in the Cameroon 5 (mean IOP was $36.9 \pm 13.8 \mathrm{mmHg}$, Range: $22-66$ $\mathrm{mmHg}$ at the first examination and $24.3 \pm 13 \mathrm{mmHg}$, Range: $12-29$ $\mathrm{mmHg}$ at the last examination). The mean IOP at last follow up is comparatively lower in our study, even though three of our cases are 
still uncontrolled. Of the 22 patients whose IOP were controlled, none of them required a surgical filtering procedure. 20 of these patients were controlled by conservative treatment (use of single or dual topical anti-glaucoma drugs or by observation) and the remaining 2 patients had surgical intervention (Small Incision Cataract Surgery [SICS] in both cases). The topical medications used varied and was based upon clinical judgement. They included mostly beta-blockers (timolol maleate) and alpha- 2 agonists (brimonidine). From Figure 2 we can notice that 5 of our patients required no intervention, which means that these patients can maintain a regular IOP (and also a stable glaucoma status) with their post-traumatic aqueous outflow pathways. The two patients who had SICS done were done primarily to relieve visual compromise due to cataract. As we saw they benefited additionally with a reduction in their IOP post-surgery. Three patients (12\%) whose IOP were not controlled, even after the use of three topical drugs, were advised for filtering surgery. The VA for 23 patients (92\%) either remained stable or improved, in $2(8 \%)$ patients the VA worsened. In the latter two patients, the decrease in VA over the follow-up period was due to progression of cataract. The last recorded VA of patients in the follow-up showed 7 patients (28\%) having a VA of 6/18 and better, whilst 13 patients (52\%) had a VA ranging from $6 / 24$ to $3 / 60.5$ patients $(20 \%)$ had a VA of CF at $1 / 2 \mathrm{~m}$ and worse. The VA remained stable or improved in most of our patients, even though majority of our patients fell within the category ranging from $6 / 24$ to $3 / 60$. In most cases, the poor status of VA was due to a combination of causes including primary damage due to injury and glaucomatous damage due to delayed presentation. We consider it significant to note that $88 \%$ of our patients could have been managed conservatively and without non-filtering surgical procedures. In 3 of our patients the IOP were not controlled Figure 2, after being treated with topical medications, and their management options are presently being reviewed. Most studies suggest that management of ARG cases, as stated earlier, should be in a step-wise manner. First medically, then via laser therapy and for those that do not respond to these, there are surgical options available $[9,10]$. Two studies, one from Israel [31] and another from Japan [32] have shown good results with laser trabeculopuncture. When medical and laser therapies have failed, an incisional outflow operation is usually indicated such as trabeculectomy with mitomycin C [11-13] or implant. Trabeculectomy with mitomycin $\mathrm{C}$ has shown to be most effective even though there are risks of bleb failure $[33,34]$ and bleb infection [11].

\section{Conclusion}

Angle recession glaucoma can cause further loss of vision in ocular trauma patients who may already have compromised vision due to injury. Control of intra-ocular pressure and preservation of presenting visual acuity was seen in most cases with conservative management with topical medications and sustained follow-up. Patients sustaining blunt ocular trauma, especially those associated with hyphaema, should be advised for future follow up and have gonioscopic evaluation of the angle. All cases had an angle recession more than 180 degrees.

\section{Acknowledgement}

Glaucoma Clinic, CEITC.

\section{Conflict of Interest}

None.

\section{References}

1. Blanton FM (1964) Anterior chamber angle recession and secondary glaucoma. A study of the aftereffects of traumatic hyphemas Arch Ophthalmol 72: 39-43.

2. Canavan YM, Archer DB (1982) Anterior segment consequences of blunt ocular injury. Br J Ophthalmol 66(9): 549-55.

3. Mooney D (1973) Angle recession and secondary glaucoma. Br J Ophthalmol 57(8): 608-612.

4. Yadava U, Dewan T, Krishna V, Das JC (2002) Traumatic glaucoma profile in an urban referral center. Annals of Ophthalmology 34(2): 118-122.

5. Kaufman JH, Tolpin DW (1974) Glaucomas after traumatic angle recession-A ten-year prospective study. Am J Ophthalmol 78(4): 648654.

6. Girkin CA, McGwin G Jr, Cherie Long, Robert Morris, Ferenc Kuhn (2005) Glaucoma after ocular contusion: a cohort study of the US Eye Injury Registry. J Glaucoma 14(6): 470-473.

7. Sihota R, Sood NN, Agarwal HC (1995) Traumatic glaucoma. Acta Ophthalmol Scand 73(3): 252-254.

8. Wolff SM, Zimmerman LE (1962) Chronic secondary glaucoma: associated with retrodisplacement of iris root and deepening of the anterior chamber angle secondary to contusion. Am J Ophthalmol 54: 547-563.

9. Allingham RR, Damji K, Freedman S (2005) Shields' Textbook of Glaucoma. ( $5^{\text {th }}$ Edn.), Philadelphia: Lippincott Williams \& Wilkins, pp. 406-407.

10. Ritch R, Shields MB, Krupin T (1996) The Glaucomas: Volume II - Clinical Sciences. (2 ${ }^{\text {nd }}$ Edn.), Missouri, Mosby, Pp. 1266-1268.

11. Mermoud A, Salmon JF, Barron A, C Straker, A D Murray (1993) Surgical management of post-traumatic angle recession glaucoma. Ophthalmology 100(5): 634-642.

12. Schlote T, Rohrbach M (2005) Traumatic glaucoma--a survey. Klin Monatsbl Augenheilkd 222(10): 772-782.

13. Manners T, Salmon JF, Barron A, Willies C, Murray AD (2001) Trabeculectomy with mitomycin $\mathrm{C}$ in the treatment of post-traumatic angle recession glaucoma. Br J Ophthalmol 85(2): 159-163.

14. Negrel AD (1997) Magnitude of Eye Injuries Worldwide. J Comm Eye Health 10(24): 49-53.

15. Thylefors B (1992) Epidemiological patterns of ocular trauma. Aust N Z J Ophthalmol 20(2): 95-98.

16. Herschler J (1977) Trabecular damage due to blunt anterior segment injury and its relationship to traumatic glaucoma.

Trans Sect Ophthalmol Am Acad Ophthalmol Otolaryngol 83(2): 239-248.

17. Ellong A, C Ebana Mvogo, E Nyouma Moune, A Bella-Hiag, A Ngosso, et al. (2005) Post-traumatic glaucoma with irido-corneal angle injuries in Cameroon. Bull Soc Belge Ophthalmol 298: 21-28.

18. Malik S, Choudhry S, Singh G (1973) Traumatic recession of the angle of anterior chamber. Indian J Ophthalmol 21(2): 68-72.

19. Krishnaiah S, Praveen K Nirmalan, Bindiganavale R Shamanna, Marmamula Srinivas, Gullapalli N Rao, et al. (2006) Ocular trauma in a Rural Population of Southern India: The Andhra Pradesh Eye Disease Study. Ophthalmology 113(7): 1159-1164 
20. Malla BK (2004) Structural changes in ocular trauma and the visual outcome. Kathmandu Univ Med J (KUMJ) 2(2,6): 113-118.

21. Babar TF, Muhammad Tariq Khan, Mir Zaman Marwat, Shafqat Ali Shah, Yasir Murad, et al. (2007) Patterns of Ocular Trauma. J Coll Physicians Surg Pak 17(3): 148-153.

22. Saxena R, Rajesh Sinha, Amitabh Purohit, Tanuj Dada, Rasik B Vajpayee, et al. (2002) Pattern of Pediatric Ocular Trauma in India. Indian J Pediatr 69(11): 863-867.

23. McGwin G, Xie A, Owsley C (2005) The Rate of Eye Injury in the United States. Arch Ophthalmol 123(7): 970-976.

24. McGwin G, Hall TA, Xie A, Owsley C (2006) Trends in Eye Injury in the United States, 1992-2001. Invest Ophthalmol Vis Sci 47: 521-527.

25. Qureshi MB (1997) Ocular Injury Pattern in Turbat, Baluchistan, Pakistan. J Comm Eye Health 10(24): 57-58.

26. Sihota R, Kumar S, Viney Gupta, Tanuj Dada, Seema Kashyap, et al. (2008) Early predictors of traumatic glaucoma after closed globe injury: trabecular pigmentation, widened angle recess, and higher baseline intraocular pressure. Arch Ophthalmol 126(7): 921-926.

27. Ozer PA, Yalvac IS, Satana B, Eksioglu U, Duman S (2007) Incidence and and risk factors in secondary glaucomas after blunt and penetrating ocular trauma. J Glaucoma 16(8): 685-690.
28. Stefan C, Rădulescu D, R Cucea, A Nicolae, A Muşat, et al. (2000) Postcontusion glaucoma. Oftalmologia 52(3): 41-43.

29. Firoozeh R, Seyed-Farzad M (2006) Angle Recession in Fireworksrelated Blunt Eye Injuries with Hyphaema. Asian J Ophthalmol 8: 62-65.

30. Melamed S, Ashkenazi I, Gutman I, Blumenthal M. (1992) NdYAG laser trabeculopuncture in angle-recession glaucoma. Ophthalmic Surg 23(1): 31-35.

31. Fukuchi T, Iwata K, Sawaguchi S, T Nakayama, J Watanabe (1993) NdYAG laser trabeculopuncture (YLT) for glaucoma with traumatic angle recession. Graefes Arch Ophthalmol 231: 571-576.

32. Mermoud A, Salmon JF, Straker C, AD Murray (1993) Post-traumatic angle recession glaucoma: a risk factor for bleb failure after trabeculectomy. $\mathrm{Br}$ J Ophthalmol 77: 631-634.

33. Salmon JF, Mermoud A, Ivey A, SA Swanevelder, M Hoffman (1994) The detection of post-traumatic angle recession by gonioscopy in a population-based glaucoma. Ophthalmology 101: 1844-1850.

34. Filipe JA, Barros H, Castro-Correia J (1997) Sports related ocular injuries-A three-year follow-up study. Ophthalmology 104(2): 313-338. 